\title{
Polyamine and ethylene changes during floral initiation in response to paclobutrazol in mango (Mangifera indica $\mathbf{L}$.)
}

\author{
G. V. Bindu ${ }^{1}$, Maryada Sharma ${ }^{2}$, Kaushal .K. Upreti ${ }^{3}$
}

Division of Plant Physiology \& Biochemistry, ICAR-Indian Institute of Horticultural Research, Hessaraghatta Lake PO, Bengaluru, Karnataka 560089, India

\begin{abstract}
Use of paclobutrazol is common strategy for inducing uniform and profuse flowering in mango. The possible mechanism by which paclobutrazol exert such responses are less understood. The present investigation was carried out to investigate possible role of polyamines and ethylene biosynthesis in the paclobutrazol induced floral induction in mango. Following paclobutrazol soil drenching application $\left(1.25 \mathrm{~g} \mathrm{a.i.} \mathrm{m}^{-1}\right)$ to mango $\mathrm{cv}$. Totapuri, the free polyamine contents, ethylene production, 1-amino cyclopropane carboxylic acid (ACC) content and ACC oxidase activity were determined in the apical buds and leaves of growing shoots at 4 distinct bud developmental stages numerically characterized as 510 (initiation of bud swelling), 511 (swollen buds), 513 (bud burst) and 515 (panicle emergence) according to standard BBCH scale. The total free polyamines, spermidine and spermine contents increased and ethylene production, ACC content and ACC oxidase activity decreased in the buds and leaves of paclobutrazol treated as compared to untreated trees. In general under paclobutrazol treatment, buds accumulated more polyamines than the leaves. With respect to the bud growth stages, total free polyamines, spermidine and spermine were high at 510/511 stage both in the paclobutrazol treated and untreated trees which declined progressively as shoots approached panicle emergence stage (515). The ethylene production, ACC and ACC oxidase activity exhibited trends opposite to that of polyamines. The study showed that polyamine - ethylene balance may control paclobutrazol induced floral bud induction in mango and accumulation of polyamines-spermidine and spermine in buds appeared as an important factor in facilitating floral induction response.
\end{abstract}

Keywords-Ethylene biosynthesis, mango flowering, paclobutrazol, polyamines.

\section{INTRODUCTION}

Mango (Mangifera indica L.) is considered one of the important widely cultivated fruit crops of India in an estimated area of 2.54 million hectare with 18.08 million tonnes of fruit production. However, productivity $\left(6.8 \mathrm{t} \mathrm{ha}^{-1}\right)$ and market share of mango export in India is low due to the problems of alternate bearing, poor fruit set, early fruit drop, absence of efficient size controlling rootstock etc. Flowering is the key developmental event for crop yield and production. The intensity and timing of flowering show strong dependence on physiological status of growing buds, hormonal interactions, environmental factors and nutrient availability (Bernier and Perilleux 2005). In mango, the flowering is a complex process that involves differentiation of apical buds under the influence low temperature and/or attaining of certain degree of shoot maturity followed by bud burst and panicle emergence (Davenport 2007). Nunez-Elisea and Davenport (1995) reported that the temperature around $15-18{ }^{\circ} \mathrm{C}$ and 6-8 month old matured shoots exhibit strong behavior for floral growth initiation in mango. Ramirez and Davenport (2010) suggested involvement of leaf synthesized and phloem mobile florigenic promoter which moves to buds under the influence cold inductive conditions for exhibiting of floral growth in mango. Upreti et al. (2013) showed high accumulation of abscisic acid (ABA) and cytokinins and reduction in gibberellins in the growing buds linked to floral induction in mango. Similarly Upreti et al. (2014) reported high levels of sucrose and glucose contributed to the formation of generative buds in mango. However, flowering process in mango still remains unelucidated because of fragmentary information on various aspects of floral development including physiological, biochemical and molecular aspects.

Use of growth retardants is an important horticultural practice for the management of reproductive growth and productivity enhancement in number of fruit crops including mango. Among the growth retardants, use of paclobutrazol [(2RS, 3RS)-1(4-chlorophenyl)-4,4 dimethyl-2-(1,2,4-triazol)-1-yl)-pentane-3-ol] has been shown beneficial in restriction of vegetative growth and successful induction of floral growth in many mango cultivars (Yadav et al. 2005; Kishore et al. 2015). Evidences have shown that the paclobutrazol induced floral development is linked to suppression of gibberellins and increase in ABA and cytokinins besides increases in shoot C: N ratio and leaf water potential (Upreti et al. 2013). Several investigations have described polyamines, important polycationic growth regulatory molecules, as facilitators of reproductive development by sensitizing floral induction, floral differentiation, floral initiation and pollination in number of crops (Pritsa 
and Voyiatzis 2004; Kakkar and Sawhney 2002, Liu et al. 2006; Aloisi et al. 2016). Rey et al. (1994a) suggested the spermine accumulation as potential physiological marker for ascertaining timing of flower induction. In another study, Rey et al. (1994b) showed that high endogenous spermidine and spermine levels with low putrescine in buds and leaves are vital to flowering process in hazelnut trees. In strawberry, polyamines are reported to be involved in regulating floral initiation (Tarenghi and Martin-Tanguy 1995). Zhu et al. (1999) in apple stated active role for spermine in the modulation of floral bud growth activity. Similarly, Kushad and Orvos (1990) reported that the reproductive structures in citrus accumulated high polyamine levels. Wang et al. (1985) in the flower buds of cherry species (Prunus avium L. and P. serrulata L.) reported that the polyamines were actively present in all stages of bud development stages and their levels were low during dormancy, which increased rapidly upon the dormancy break and floral induction. Importance of polyamine involvement in flowering process has also been confirmed through their exogenous applications in varied crops. In apple trees, polyamines application through cut pedicels enhanced the number of flower buds (Rohozinski et al. 1986) and spraying polyamines favouring flower bud formation (Costa and Bagni 1983). Similarly, promotion of flowering by exogenous polyamines has been demonstrated in Spirodela punctata and morning glory (Liu et al. 2006). Tarenghi and Martin-Tanguy (1995) on the other hand by employing inhibitor of polyamine biosynthesis, $\alpha$-difluoromethylornithine (DFMO) reported that the inhibition in flowering in strawberry was related polyamine decrease, which was restored by exogenous application of putrescine. Despite the importance of polyamines in floral development of different fruit crops, studies attributing polyamine involvement in floral induction of mango are lacking. Considering the fact that the biosynthesis of polyamines and ethylene are corregulated as a result of sharing of common precursor, s-adenosine methionine (SAM) (Yang 1987), and importance of ethylene in the promotion of flowering in many fruit crops including mango (Bukovac et al. 2006; Turnbull et al. 1999; Davenport and Nunez-Elisea 1990), we in the present investigation studied the effects of paclobutrazol on polyamine contents, ethylene production, ethylene precursor 1-aminocyclopropane carboxylic acid (ACC) content and activity of enzyme facilitating ACC to ethylene conversion- ACC oxidase at different stages of floral bud growth in the cv. Totapuri to delineate the role of polyamines in paclobutrazol induced flowering in mango.

\section{MATERIALS AND METHODS}

The studies were conducted during the years 2014-2015 at the experimental farm of ICAR-Indian Institute of Horticultural Research, Hessaraghatta, Bengaluru on 18 years aged trees of a regular bearing mango cv. Totapuri maintained at $10 \times 10 \mathrm{~m}$ spacing. The trees were given single recommended dose of paclobutrazol (Zeneca Limited, Surry, UK) at $1.25 \mathrm{~g}$ a.i. per $\mathrm{m}$ of canopy diameter as soil drenching treatment by spreading uniformly in a circular band of $25 \mathrm{~cm}$ width around the tree at a radial distance of $1.0 \mathrm{~m}$ from tree trunk during $3^{\text {rd }}$ week of August. The untreated trees (control) were given water similarly. Four trees were maintained under paclobutrazol treatment and another four trees under control. Recommended package of practices were adopted for maintenance of trees. During the experimentation period, the average minimum and maximum temperatures were 20.2 and $28.1^{\circ} \mathrm{C}$ and average relative humidity was $63.2 \%$. The terminal shoots measuring about $20 \mathrm{~cm}$ length from current year growth were labeled in different directions of paclobutrazol treated and untreated trees. Periodic sampling of apical buds and leaves was carried out from $3^{\text {rd }}$ week of September for free polyamines, ethylene production, ACC and ACC oxidase activity at four phenological stages of bud development characterized as 510 (initiation of bud swelling), 511 (swollen buds), 513 (bud burst) and 515 (panicle emergence) according to pheno-phase guide chart described by Shailendra Rajan et al. (2011).

\subsection{Polyamine analysis}

The free polyamine contents in the apical buds and leaves were estimated according to the HPLC procedure of Flores and Galston (1982) with some modifications. The buds (1.0 g) and leaves $(2.0 \mathrm{~g})$ were homogenized in $10 \mathrm{ml}$ of chilled $5 \%(\mathrm{v} / \mathrm{v})$ perchloric acid, contents centrifuged and the supernatant separated out. One ml of $2.0 \mathrm{~N} \mathrm{NaOH}$ and $100 \mu \mathrm{l}$ of benzoyl chloride were added to $1.0 \mathrm{ml}$ of supernatant, for conversion of polyamines to their benzoyl derivative. After adding $1.0 \mathrm{ml}$ of saturated $\mathrm{NaCl}$, the benzoylated polyamines were extracted with equal volume of chilled diethyl ether. The ether phase was separated out and dried under nitrogen. The residue was suspended in $1.0 \mathrm{ml}$ methanol and clarified by passing through membrane filters (pore size $0.20 \mu \mathrm{m}$ pore size, $13 \mathrm{~mm}$ diameter; Millipore, USA). The methanolic extract was dried under nitrogen at $40{ }^{\circ} \mathrm{C}$ and further dissolved in $100 \mu \mathrm{l}$ of methanol for HPLC (Model: Prominence, Shimadzu, Japan) equipped with Synergi $4 \mu$ Fusion-RP 80A column $(25 \mathrm{~cm} \times 4.6 \mathrm{~mm}$, Phenomenex, USA) and Photodiode Array Detector (Model: SPD 20, Shimadzu, Japan) adjusted to a wavelength of $282 \mathrm{~nm}$. An isocratic solvent system comprising of methanol (62\%, v/v) containing $1 \%$ acetic acid at $1.0 \mathrm{ml} \mathrm{min}{ }^{-1}$ flow rate was employed to separate and quantify component polyamines. The retention times for standard putrescine, spermidine and spermine were 5.8, 7.1, and 8.6 minutes, respectively under above 
HPLC conditions. The quantification of free polyamines was carried out employing putrescine, spermidine and spermine standards (Sigma, USA).

\subsection{Ethylene concentration}

The sampling of apical buds and leaves for determining ethylene concentrations was carried out in pre-weighed $5.0 \mathrm{ml}$ sampling tubes and $50 \mathrm{ml}$ conical flasks, respectively fitted with rubber septa. The samples were incubated for $3 \mathrm{~h}$ at $37{ }^{\circ} \mathrm{C}$ and ethylene concentration was determined on Gas Liquid Chromatograph (GLC) (Auto System XL, Perkin Elmer, USA) equipped with Porapak-N column (2.0 m length, 80x100 mesh) and flame ionization detector (FID) according to Galliard and Grey (1969). The column, injection port and detector temperatures employed were 75,125 and $200{ }^{\circ} \mathrm{C}$, respectively and the carrier gas $\left(\mathrm{N}_{2}\right)$ flow rate was $45 \mathrm{ml} \mathrm{min}^{-1}$. Standard ethylene $\left(100 \mu 1 \mathrm{~L}^{-1}\right.$ nitrogen $)$ was used to quantify ethylene.

\subsection{1-aminocyclopropane carboxylic acid (ACC) content}

ACC content was determined using indirect method following oxidation of ACC to ethylene according to Lizada and Yang (1979). The samples of apical buds or leaves (500 mg lyophilized powder) were suspended in $4.0 \mathrm{ml} \mathrm{of} \mathrm{cold} 5.0 \%$ sulphosalicyclic acid, contents vortexed and further centrifuged at $5000 \mathrm{rpm}$ for $15 \mathrm{~min}$ at $4{ }^{\circ} \mathrm{C}$. The supernatant separated out was lyophilized. The lyophilized samples were dissolved in $1.0 \mathrm{ml}$ of deionized water and purified over Dowex 50[H+] syringe column. The ACC was eluted with $4.0 \mathrm{M}$ of ammonium hydroxide, eluate dried under vacuum and dissolved in 1.0 $\mathrm{ml}$ of deionized water. The ACC was estimated by adding $50 \mu \mathrm{l}$ mercuric chloride to the aqueous ACC sample in a $2.0 \mathrm{ml}$ glass vial kept in an ice bath and fitted with rubber septa. A $100 \mu \mathrm{l}$ of $\mathrm{NaOCl}$ and saturated $\mathrm{NaOH}(2: 1$, v/v) solution was injected into the vial, mixture vortexed vigorously for $3 \mathrm{~min}$ and further cold incubated for 5 min at $4{ }^{\circ} \mathrm{C}$. The ethylene produced was quantified by GLC as stated above and quantification of ACC was carried out using standard ACC (Sigma, USA). The conversion efficiency of ACC to ethylene determined was $78.43 \%$.

\subsection{ACC-oxidase activity}

The apical buds and leaves powdered using liquid nitrogen of $(250 \mathrm{mg}$ ) were kept in $2.0 \mathrm{ml}$ sample tubes containing $500 \mu \mathrm{l}$ of ACC $(5.0 \mu \mathrm{mol})$. The tubes sealed tightly with rubber septa were incubated for $4 \mathrm{~h}$ at $37^{\circ} \mathrm{C}$ in an orbital shaker at $90 \mathrm{rpm}$. The conversion of ACC to ethylene was measured by assaying ethylene produced employing GLC-FID and ACC oxidase activity was expressed as $\mathrm{n}$ mol ethylene formed $\mathrm{g}^{-1} \mathrm{hr}^{-1}$.

\subsection{Statistical analysis}

All the data were analyzed using Agri Stat software and the Student Tukeys test of significance was performed to determine significance between the data obtained for different parameters at different stage of bud development.

\section{RESULTS AND DISCUSSION}

The free polyamine contents varied distinctly in the apical buds and leaves of paclobutrazol untreated and treated trees at different stages of bud growth, and the apical buds exhibited higher contents than the leaves (Table 1). In the untreated trees, the spermidine, spermine and putrescine contents decreased in both apical buds and leaves upon advancing of stage from 510 to 515 , and the spermidine ( 43.48 and $15.76 \mathrm{~m} \mathrm{~mol} \mathrm{~g}^{-1}$ ) followed by spermine ( 35.07 and $\left.12.63 \mathrm{~m} \mathrm{~mol} \mathrm{~g}^{-1}\right)$ contents were the highest in the buds and leaves at 510 stage. Following the paclobutrazol application, the total polyamine, putrescine, spermidine and spermine contents increased by 31.90-91.20\%, 15.09-31.58\%, 40.96-123.18\% and 33.17-94.10\% in apical buds and by $11.05-21.77 \%, 4.02-13.91 \%, 12.90-25.95 \%$ and $13.59-22.49 \%$ in leaves, respectively as compared to untreated trees, and increase was high in spermidine at 510 followed by 511 stages and in spermine content at 511 stage (Table 1). In general, the trends in the contents of different polyamines across the bud growth stages broadly resembled in the paclobutrazol treated and untreated trees.

In paclobutrazol untreated trees, the ethylene production, ACC content and ACC-oxidase activity showed increasing trends from 34.71-58.71 $\mathrm{nl} \mathrm{g}^{-1} \mathrm{~h}^{-1}, 5.36-12.94 \mathrm{n} \mathrm{mol} \mathrm{g}^{-1}$ and 13.96-21.24 $\mathrm{nl} \mathrm{g}^{-1} \mathrm{~h}^{-1}$ in apical buds and 16.96-23.14 $\mathrm{nl} \mathrm{g}^{-1} \mathrm{~h}^{-1}, 1.76-2.86$ $\mathrm{n} \mathrm{mol} \mathrm{g} \mathrm{g}^{-1}$ and 4.68-6.52 $\mathrm{nl} \mathrm{g}^{-1} \mathrm{~h}^{-1}$ in leaves during the floral bud development stages, respectively (Table 2). Following paclobutrazol treatment, the ethylene production, ACC content and ACC-oxidase activity declined both in buds and leaves, with buds being more responsive than the leaves. Between the stages, all these parameters revealed high values at 515 (panicle emergence) and low values at 510 stages. 
TABLE 1

Effect of Paclobutrazol (PBZ) on Polyamine Contents at Various Developmental Stages of Bud in Mango CV. Totapuri (Data REPRESENT MEAN $\pm \mathrm{SE}, \mathrm{N}=4$ )

\begin{tabular}{|c|c|c|c|c|c|c|c|c|c|}
\hline \multirow{3}{*}{ Treatments } & \multirow{3}{*}{$\begin{array}{l}\text { Polyamines } \\
\left(\mathrm{n} \mathrm{mol} \mathrm{g}^{-1}\right)\end{array}$} & \multicolumn{4}{|c|}{ Apical buds } & \multicolumn{4}{|c|}{ Leaves } \\
\hline & & \multicolumn{8}{|c|}{ Floral bud development stages } \\
\hline & & 510 & 511 & 513 & 515 & 510 & 511 & 513 & 515 \\
\hline \multirow{4}{*}{$-\mathbf{P B Z}$} & Putrescine & $15.63 \pm 0.94$ & $17.78 \pm 0.91$ & $15.22 \pm 0.85$ & $12.66 \pm 1.03$ & $9.56 \pm 1.01$ & $9.97 \pm 1.15$ & $7.56 \pm 1.22$ & $6.22 \pm 0.45$ \\
\hline & Spermidine & $43.48 \pm 3.91$ & $34.45 \pm 3.05$ & $26.21 \pm 1.11$ & $20.73 \pm 0.42$ & $15.76 \pm 1.89$ & $13.24 \pm 1.08$ & $11.252 \pm 0.74$ & $10.85 \pm 0.16$ \\
\hline & Spermine & $30.07 \pm 1.85$ & $28.31 \pm 2.62$ & $21.01 \pm 1.62$ & $19.81 \pm 1.19$ & $12.63 \pm 1.22$ & $10.18 \pm 1.36$ & $7.36 \pm 0.52$ & $5.56 \pm 0.64$ \\
\hline & Total polyamines & $94.48 \pm 6.29$ & $80.54 \pm 6.49$ & $62.44 \pm 3.48$ & $53.20 \pm 2.59$ & $37.95 \pm 4.19$ & $33.39 \pm 3.59$ & $26.17 \pm 2.56$ & $22.63 \pm 1.29$ \\
\hline \multirow{4}{*}{$+\mathbf{P B Z}$} & Putrescine & $20.96 \pm 1.06$ & $22.51 \pm 1.68$ & $17.86 \pm 1.28$ & $14.47 \pm 0.96$ & $10.89 \pm 1.78$ & $11.23 \pm 0.93$ & $8.26 \pm 0.76$ & $6.47 \pm 0.88$ \\
\hline & Spermidine & $55.04 \pm 7.52$ & $62.61 \pm 5.17$ & $25.02 \pm 1.43$ & $15.72 \pm 1.32$ & $19.85 \pm 2.23$ & $15.85 \pm 1.33$ & $13.29 \pm 0.43$ & $12.25 \pm 0.32$ \\
\hline & Spermine & $48.65 \pm 3.68$ & $38.95 \pm 2.81$ & $34.99 \pm 2.13$ & $26.38 \pm 1.64$ & $15.47 \pm 1.88$ & $12.12 \pm 1.24$ & $8.36 \pm 0.57$ & $6.41 \pm 0.64$ \\
\hline & Total polyamines & $124.65 \pm 12.32$ & $124.07 \pm 9.52$ & $76.17 \pm 4.76$ & $51.57 \pm 3.85$ & $46.21 \pm 4.29$ & $39.20 \pm 2.56$ & $29.91 \pm 1.69$ & $25.13 \pm 1.89$ \\
\hline
\end{tabular}

Codes of bud developmental stages: 510 (bud swelling), 511 (swollen buds), 513 (bud burst) and 515 (panicle emergence) according to standard BBCH scale

TABLE 2

Effect of Paclobutrazol (PBZ) on Ethylene Production, Acc Content And AcC Oxidase ACtivity at VArious Developmental STAGES OF BUD IN MANGO CV. TOTAPURI (DATA REPRESENT MEAN \pm SE, N = 4)

\begin{tabular}{|c|c|c|c|c|c|c|c|c|c|}
\hline \multirow{3}{*}{ Treatments } & \multirow{3}{*}{ Parameters } & \multicolumn{4}{|c|}{ Apical buds } & \multicolumn{4}{|c|}{ Leaves } \\
\hline & & \multicolumn{8}{|c|}{ Floral bud developmental stages } \\
\hline & & 510 & 511 & 513 & 515 & 510 & 511 & 513 & 515 \\
\hline \multirow{3}{*}{$-\mathbf{P B Z}$} & Ethylene production $\left(\mathrm{nl} \mathrm{g}^{-1} \mathrm{~h}^{-1}\right)$ & $34.71 \pm 3.14$ & $30.22 \pm 2.84$ & $43.89 \pm 4.86$ & $58.26 \pm 6.04$ & $23.14 \pm 1.92$ & $18.27 \pm 1.58$ & $16.96 \pm 1.13$ & $20.14 \pm 2.17$ \\
\hline & $\mathrm{ACC}\left(\mathrm{n} \mathrm{mol} \mathrm{g}^{-1}\right)$ & $5.36 \pm 4.52$ & $7.24 \pm 0.78$ & $9.16 \pm 0.92$ & $12.94 \pm 1.17$ & $1.76 \pm 0.12$ & $2.16 \pm 0.23$ & $2.86 \pm 0.23$ & $2.74 \pm 1.62$ \\
\hline & ACC oxidase activity $\left(\mathrm{nl} \mathrm{g}^{-1} \mathrm{~h}^{-1}\right)$ & $13.96 \pm 1.15$ & $13.41 \pm 1.26$ & $16.92 \pm 1.72$ & $21.24 \pm 1.73$ & $4.68 \pm 0.52$ & $6.05 \pm 0.73$ & $5.16 \pm 0.31$ & $6.52 \pm 0.74$ \\
\hline \multirow{3}{*}{$+\mathbf{P B Z}$} & Ethylene production $\left(\mathrm{nl} \mathrm{g}^{-1} \mathrm{~h}^{-1}\right)$ & $23.32 \pm 1.96$ & $25.23 \pm 2.17$ & $27.15 \pm 2.07$ & $34.22 \pm 3.67$ & $17.68 \pm 1.12$ & $14.63 \pm 1.13$ & $14.15 \pm 1.39$ & $18.12 \pm 1.63$ \\
\hline & $\mathrm{ACC}\left(\mathrm{n} \mathrm{mol} \mathrm{g}^{-1}\right)$ & $4.61 \pm 0.21$ & $5.43 \pm 0.46$ & $6.66 \pm 0.51$ & $9.02 \pm 1.03$ & $1.51 \pm 0.11$ & $1.89 \pm 0.01$ & $2.66 \pm 0.24$ & $2.31 \pm 0.24$ \\
\hline & ACC oxidase activity $\left(\mathrm{nl} \mathrm{g}^{-1} \mathrm{~h}^{-1}\right)$ & $9.42 \pm 0.72$ & $11.14 \pm 1.19$ & $13.66 \pm 1.19$ & $16.89 \pm 1.45$ & $3.14 \pm 0.35$ & $2.64 \pm 0 . .22$ & $3.72 \pm 0.33$ & $4.65 \pm 0.53$ \\
\hline
\end{tabular}

Codes of bud developmental stages: 510 (bud swelling), 511 (swollen buds), 513 (bud burst) and 515 (panicle emergence) according to standard BBCH scale 
The floral morphogenesis involves complex system of involvement and interaction of biochemical signals including plant growth regulators (Davis 2009). Among the growth regulators, polyamines are ascribed as important elicitor of floral morphogenesis and floral initiation in a wide range of crops (Rey et al. 1994a, b; Tarenghi and Martin-Tanguy 1995; Zhu et al. 1999; Kushad and Orvos 1990; Wang et al. 1985). Such effects are attributed to the ability of polyamine to sensitize cell cycle regulation for supporting proliferation and differentiation processes (Baron and Stasolla 2008). Besides, these also suffice partially the high metabolic demand of florally differentiating tissues through recycling of $\mathrm{C}$ and $\mathrm{N}$, and in optimization of enzyme activities associated with nucleic acid and protein biosynthesis (Sarjala and Savonen 1994). Sood and Nagar (2004) reported that the high polyamine levels facilitate active cell division for triggering floral growth. The role of polyamines in flowering has been documented by Galston and Sawhney (1990) and Bagni et al. (1993). In support of polyamine involvement in reproductive growth, Hanzawa et al. (2002) and Alcazar et al. (2005) reported that the polyaminedeficient mutants or mutants with unbalanced polyamine metabolism exhibit abnormal growth and flowering patterns as well as delayed flowering. Thus, the results showing increased free polyamines content in buds and leaves of growing shoots of paclobutrazol treated trees in this investigation are indicative of polyamine involvement in the paclobutrazol mediated floral bud differentiation. Since polyamine and ethylene share common intermediate, SAM for their biosynthesis, diversion of SAM for polyamine synthesis following paclobutrazol application could possibly account for polyamine increase and reductions in ethylene as evident from the study. Murti and Upreti (2005) reported decline in ethylene biosynthesis by paclobutrazol in mango in relation to vigour regulation. The paclobutrazol induced increase in polyamines could also be due to stimulation in synthesis of polyamines or arresting of their degradation by oxidases. However, this aspect needs investigation. Further, the increase in polyamines might be consequence of possible interaction effects of polyamines with cytokinins and ABA, as these tend to upregulate polyamine biosynthesis. Liu et al. (2013) reported interaction of polyamines with cytokinins and ABA in relation to reproductive development in wheat. Mukhopadhyay et al. (1983) reported increase in polyamines following cytokinins treatment. Similarly ABA favouring polyamine increase has been documented by Kuznetsov et al. (2006). In the earlier studies, Upreti et al. (2013) and Burondkar et al. (2016) witnessed increases in ABA and cytokinins during floral induction in mango following paclobutrazol application.

Furthermore, with respect to bud growth, free polyamine contents varying distinctly were high at initial bud development stages which declined by late bud development stages. In contrast, ethylene and its precursor, ACC exhibited opposite patterns. Since biosynthesis involves conversion of ACC produced by SAM and MACC by involving ACC-oxidase enzyme, the consistency in pattern of ethylene, ACC and ACC-oxidase activity across bud growth stages in paclobutrazol treated and untreated trees depicted that the declined availability of ACC coupled with inhibition in ACC-oxidase activity were associated to paclobutrazol induced reduction in ethylene concentrations. Thus [2] polyamine and ethylene balance favouring polyamine formation is vital for paclobutrazol induced floral bud differentiation in mango. The increase in ethylene with reductions in polyamine at late bud growth stages (panicle emergence) evident from the study could be linked to ethylene association in panicle emergence, since promotory to flowering mango (Chadha and Pal 1986; Saidha et al. 1983). Davenport and Nunez-Elisea (1990) based on lack of correlation between ethylene productions and flowering also suggested that the floral induction of mango is not mediated by ethylene produced in leaves or buds.

Among the different component polyamines, the spermidine followed by spermine contents were distinctly high both in paclobutrazol untreated and treated trees at initial stages of floral bud development. This revealed that spermidine and spermine are more associated for paclobutrazol induced floral bud formation in mango, and such effects could be linked to their greater effectiveness in supporting cell division activity and organogenesis as reported by Kuznetzov et al. (2002), possibly due to their better cell membrane stabilization potential as a result of inherent trivalent and tetravalent nature. Besides, some studies have also reported direct involvement of spermidine in the floral differentiation. Ali and Lovatt (1995) documented that the spermidine availability at the time of flower initiation and organogenesis is an important factor for floral growth in 'Washington' navel orange. Similarly, Huang et al. (2004) and Kaur-Sawhney et al. (1988) reported high spermidine content beneficial for floral initiation in Polianthes tuberosa L. and tobacco, respectively. Also, the growing apical buds revealing higher polyamines than leaves in paclobutrazol untreated and treated trees could possibly be the reflections of translocation of polyamines from leaves to buds under given environmental conditions for eliciting floral responses. The translocation of polyamines among different organs is reported (Antognoni et al. 1998). Thus polyamines could serve as one of the potential signaling molecule for onset of floral induction in mango. 


\section{CONCLUSION}

In the conclusion, the study revealed that the polyamine and ethylene biosynthesis compete each other during paclobutrazol induced floral bud formation and an accumulation of polyamines- spermidine and spermine with reduction in ethylene biosynthesis during initial bud development stage is vital for paclobutrazol mediated floral induction process. It was also apparent that the ethylene concentration by itself did not have role to play in the paclobutrazol induced floral bud formation.

\section{ACKNOWLEDGEMENTS}

The authors are thankful to the Director of the institute for encouragement and support during the study. We gratefully acknowledge the financial support from NAIP, ICAR, New Delhi.

\section{REFERENCES}

[1] Alcazar, R., Garcia-Martinez, J.L., Cuevas, J.C., Tiburcio, A.F., Altabella, T. 2005. Over- expression of ADC2 in Arabidopsis induces dwarfism and late-flowering through GA deficiency. Plant J. 43: 425-436.

[2] Ali, A.G., Lovatt, C.J. 1995. Relationship of polyamines to low-temperature stress-induced flowering of the 'Washington' navel orange (Citrus sinensis L. Osbeck). J. Hortic. Sci. 70: 491-498.

[3] Aloisi, I., Cai, G., Serafini-Fracassini, D., Duca, S.D. 2016. Polyamines in pollen: From microsporogenesis to fertilization. Frontiers in Plant Sci. doi: 10.3389/fpls.2016.00155.

[4] Antognoni, F., Fornale, S., Grimma, C., Komor, E., Bagni, N. 1998. Long distance translocation of polyamines in phloem and xylem of Ricinus communis L. plants. Planta 204: 520-527.

[5] Bagni, N., Altamura, M.M., Biondi, S., Mengoli, M., Torrigianni, P. 1993. Polyamines and morphogenesis in normal and transgenic plant cultures. In: K.A. Roubelakis-Angelkis, K.T.T. Van (Eds), Morphogenesis in plants molecular approaches Springer Science \& Business Media, New York, pp 89-112.

[6] Baron, K., Stasolla, C. 2008. The role of polyamines during in vivo and in vitro development. In vitro Cell Develop. 44: 384-395.

[7] Bernier, G., Perilleux, C. 2005. A physiological overview of the genetics of flowering time control. Plant Biotechnol. J. 3: 3-16.

[8] Bukovac, M.J., Sabbatini, P., Schwallier, P.G. 2006. Modifying alternate bearing of spur-type 'delicious' apple with ethephon. HortScience 41: 1606-1611.

[9] Burondkar, M.M., Upreti, K.K., Ambavane, A.K., Shailendra Rajan, Mahadik, S.G., Bhave, S.G. 2016. Hormonal changes during flowering in response to Paclobutrazol application in mango cv. Alphonso under Konkan conditions. Ind. J. Plant Physiol. doi: 10.1007/s40502-016-0236-1.

[10] Chadha, K.L., Pal, R.N. 1986. Mangifera indica. In: A.C. Halevy (Ed.) CRC Handbook of Flowering, Vol 5, CRC Press, Boca Raton, Florida, pp211-230.

[11] Costa, G., Bagni, N. 1983. Effects of polyamines on fruit-set of apple. HortScience 18: 59-61.

[12] Davenport, T.L. 2007. Reproductive physiology of mango. Brazilian J. Plant Physiol. 19: 363-376.

[13] Davenport, T.L., Nunez-Elisea, R. 1990. Ethylene and other endogenous factors possibly involved in mango flowering. Acta Hort. 275: 441-447.

[14] Davis, S.J. (2009). Integrating hormones into the floral-transition pathway of Arabidopsis thaliana. Plant Cell Environ. 32: 12011210.

[15] Flores, H.E., Galston, A.W. 1982. Analysis of polyamines in higher plants by High Performance Liquid Chromatography. Plant Physiol. 69: 701-706.

[16] Galliard, T., Grey, T.C. 1969. A rapid method for the determination of ethylene in the presence of other volatile natural products. J. Chromat. 41: 442-452.

[17] Galston, A.W., Sawhney, R.K. 1990. Polyamines in plant physiology. Plant Physiol. 94: 406-410.

[18] Hanzawa, Y., Imai, A., Michael, A.J., Komeda, Y., Takahashi, T. 2002. Characterization of the spermidine synthase-related gene family in Arabidopsis thaliana. FEBS Letters 527: 176-80.

[19] Huang, C.K., Chang, B.S., Wang, K.C., Her, S.J., Chen, T.W., Chen, Y.A., Cho, C.L., Liao, L.J., Huang, K.L., Chen, W.S., Liu, Z.H. 2004. Changes in polyamine pattern are involved in floral initiation and development in Polianthes tuberosa. J. Plant Physiol. 161: 709-13.

[20] Kakkar, R.K., Sawhney, V.P. 2002. Polyamine research in plants: A changing perspective. Physiol. Plant. 116: 281-292.

[21] Kaur-Sawhney, R., Tiburcio, A.F., Galston, A.W. 1988. Spermidine and flower-bud differentiation in thin-layer explants of tobacco. Planta 173: 282-284.

[22] Kishore, K., Singh, H.S., Kurian, R.M. 2015. Paclobutrazol use in perennial fruit crops and its residual effects: A review. Ind. J. Agric.Sci. 85: 863-872.

[23] Kushad, M.M., Orvous, A.R. 1990. Relative changes in polyamines during Citrus flower development. HortScience 25: $946-948$.

[24] Kuznetsov, V., Radyukina, N.L., Shevyakova, N.I. 2006. Polyamines and stress: biological role, metabolism and regulation. Rus. J. Plant Physiol. 53: 583-604.

[25] Liu, J.H., Honda, C., Moriguchi, T. 2006. Involvement of polyamine in floral and fruit development. J. Agric. Res. Q. (JARQ) 40: 51-58. 
[26] Liu, Y., Gu, D., Wu, W., Wen, X., Liao, Y. 2013. The relationship between polyamines and hormones in the regulation of wheat grain filling. PLoS ONE 8(10): e78196. doi:10.1371/journal.pone.0078196.

[27] Lizada, M.C.C., \& Yang, S.F. (1979). A simple and sensitive assay for 1-aminocyclopropane- 1-carboxylic acid, Analytical Biochemistry, 100, 140-145.

[28] Mukhopadhyay, M., Choudhuri, M., Sen, K., \& Ghosh, B. (1983). Changes in polyamines and related enzymes with loss of viability in rice seeds. Phytochemistry, 22, 1547-1551.

[29] Murti, G.S.R., \& Upreti, K.K. (2005). Effects of paclobutrazol on leaf water potential, ethylene production, ACC, ACC-oxidase and polyamines in mango seedlings. Journal of Plant Biology, 32, 183-188.

[30] Nunez-Elisea, R., Davenport, T.L. 1995. Effect of leaf age, duration of cool temperature treatment, and photoperiod on bud dormancy release and floral initiation in mango. Scientia Hort. 62: 63-73.

[31] Pritsa, T.S., Voyiatzis, D.G. 2004. Seasonal changes in polyamine content of vegetative and reproductive olive organs in relation to floral initiation, anthesis, and fruit development. Aust. J. Agric. Res. 55: 1039-1046.

[32] Ramirez, F., Davenport, T.L. 2010. Mango (Mangifera indica L.) flowering physiology. Scientia Hort. 126: 65-72.

[33] Rey, M., Díaz-Sala, C., Rodríguez, R. 1994a. Comparison of endogenous polyamine content in hazel leaves and buds between the annual dormancy and flowering phases of growth. Physiol. Plant.. 91: 45-50.

[34] Rey, M., Diaz-Sala, C., Rodríguez, R. 1994b. Effect of repeated severe pruning on endogenous polyamine content in hazelnut trees. Physiol. Plant. 92: 487-492.

[35] Rohozinski, J., Edwards, G.R., Hoskyns, P. 1986. Effect of brief exposure to nitrogenous compounds on floral initiation in apple trees. Physiologie Vegetale 24: 673-677.

[36] Saidha, T., Rao, V.N.M., Santhan Krishnan, P. 1983. Internal leaf ethylene level in relation to flowering in mango. Ind. Hort. 40: 139-145.

[37] Sarjala, T., Savonen, E.M. 1994. Seasonal fluctuations in free polyamines in Scots pine needles. J. Plant Physiol. 144: $720-725$.

[38] Shailendra Rajan, Tiwari, D., Singh, V.K., Saxena, P., Singh, S., Reddy, Y.T.N., Upreti, K.K., Burondkar, M.M., Bhagwan, A., Kennedy, R. 2011. Application of extended BBCH scale for phenological studies in mango (Mangifera indica L.). J. Applied Hort. 13: $108-114$

[39] Sood, S., Nagar, P.K. 2004. Changes in endogenous polyamines during flower development in two diverse species of rose. Plant Growth Regul. 44: 117-123.

[40] Tarenghi, E., Martin-Tanguy, J. 1995. Polyamines, floral induction and floral development of strawberry (Fragaria ananassa Dutch.). Plant Growth Regul. 17: 157-165.

[41] Turnbull, C.G., Sinclair, E.R., Anderson, K.L., Nissen, R.J., Shorter, A.J., Lanham T.E. 1999. Routes of ethephon uptake in pineapple (Ananas comosus) and reasons for failure of flower induction. J. Plant Growth Regul. 18: 145-152.

[42] Upreti, K. K., Reddy, Y. T. N., Shivu Prasad, S. R., Bindu, G. V., Jayaram, H. L. 2013. Hormonal changes in response to paclobutrazol induced early flowering in mango cv Totapuri. Scientia Hort. 150: 414-418.

[43] Upreti, K.K., Shivu Prasad, S.R., Reddy, Y. T. N., Rajeshwara, A. N. 2014. Paclobutrazol induced changes in carbohydrates and some associated enzymes during floral initiation in mango (Mangifera indica L.) cv. Totapuri. Ind. J. Plant Physiol. 19: 317-323.

[44] Wang, S.Y., Faust, M., Steffens, G.L. 1985. Metabolic changes in cherry flower buds associated with breaking of dormancy in early and late blooming cultivars. Physiol. Plant. 65: 89-94.

[45] Yadav, R.K., Rai, N., Yadav, D.S., Asati, B.S. 2005. Use of paclobutrazol in horticultural crops-A review. Agric. Rev. 26: 124-132.

[46] Yang, S.F. 1987. The role of ethylene and ethylene synthesis in fruit ripening. In: W.W. Thompson, E.A. Nothnagel, R.C. Huffaker (Eds), Plant Senescence: Its Biochemistry and Physiology, Amer. Soc. Plant Physiologists, Rockville, MD, pp156-166.

[47] Zhu, L. H., Tromp, J., van de Peppel, O. 1999. Polyamines in buds of apple as affected by temperature and their relationship to bud development. Scientia Hort. 82: 203-216. 